\title{
Olfactory and gustatory dysfunctions due to the coronavirus disease (COVID-19): a review of current evidence
}

\author{
Esmaeil Mehraeen ${ }^{1} \cdot$ Farzane Behnezhad $^{2} \cdot$ Mohammad Amin Salehi $^{3} \cdot$ Tayebeh Noori $^{4} \cdot$ Hamid Harandi $^{3}$. \\ SeyedAhmad SeyedAlinaghi ${ }^{3}$ (i)
}

Received: 18 May 2020 / Accepted: 8 June 2020 / Published online: 17 June 2020

(c) Springer-Verlag GmbH Germany, part of Springer Nature 2020

\begin{abstract}
Introduction It is reported that coronavirus disease (COVID-19) can affect the sense of smell and taste of infected people. The pathobiology of this virus is still incompletely known, and it is therefore important to explore the impact of COVID-19 infections on olfactory and gustatory functions. We aimed to review current evidence on olfactory and gustatory dysfunctions caused by COVID-19.

Methods This study was a narrative review performed in 2020 to investigate the olfactory and gustatory dysfunctions of the COVID-19. We searched eight keywords in six databases to determine the related documents on the main objective of the study. To discover studies meeting the inclusion criteria, the authors screened the titles and abstracts of the identified articles. The appropriate studies were included and their results were discussed to make the final selection.

Results We have studied 24 current articles on the olfactory and gustatory dysfunctions due to COVID-19. A review of current studies has shown that we have a surge in the spread of olfactory and gustatory dysfunctions that happened during the epidemic of COVID-19 infection. Most studies (95.8\%) have confirmed the symptoms of anosmia in patients with SARS-CoV-2 infection. A review of current studies showed that, in addition to anosmia, evidence of ageusia and dysgeusia (parageusia) was also seen in patients with COVID-19.

Conclusion The results of our study support recent reports that SARS-CoV-2 may infect oral and nasal tissues and cause olfactory and gustatory dysfunctions. These findings may aid future research on the diagnosis, prevention, and treatment of COVID-19 consequences.
\end{abstract}

Keywords Olfactory dysfunction · Dysgeusia $\cdot$ Anosmia/hyposmia $\cdot$ COVID-19 $\cdot$ Coronavirus infections $\cdot$ SARS-CoV-2

SeyedAhmad SeyedAlinaghi

s_a_alinaghi@yahoo.com

Esmaeil Mehraeen

es.mehraeen@gmail.com

Farzane Behnezhad farzan1898@gmail.com

Mohammad Amin Salehi

mohamsa@gmail.com

Tayebeh Noori

t.noori25@gmail.com

Hamid Harandi

harandi.hamid@icloud.com
1 Department of Health Information Technology, Khalkhal University of Medical Sciences, Khalkhal, Iran

2 Department of Virology, School of Public Health, Tehran University of Medical Sciences, Tehran, Iran

3 Iranian Research Center for HIV/AIDS, Iranian Institute for Reduction of High Risk Behaviors, Tehran University of Medical Sciences, Tehran, Iran

4 Department of Health Information Technology, School of Allied Medical Sciences, Zabol University of Medical Sciences, Zabol, Iran 


\section{Introduction}

Severe acute respiratory syndrome coronavirus 2 (SARSCoV-2) was first discovered in China in late 2019 and is now an ongoing pandemic [1]. SARS-CoV-2 is known as the coronavirus, (a positive-sense single-stranded RNA, enveloped virus), and the genome size is one of the largest among RNA viruses. SARS-CoV-2 is similar to severe acute respiratory syndrome coronavirus (SARS-CoV). Previous studies have shown that the natural origin for SARS$\mathrm{CoV}-2$ is a bat [2-6]. Coronavirus disease (COVID-19) is an infectious disease ranging from a mild to more severe respiratory disease, common respiratory manifestations of COVID-19 is dry cough, fever, dyspnea, arthralgia and malaise [2,3], and less common symptoms such as nausea, vomiting, diarrhea and abdominal pain [7], is transmitted by person-to-person [2, 3]. However, in several countries such as South Korea, China, Iran and Italy reported taste and smell dysfunctions in COVID-19 infection [1,8].

SARS-CoV-2 binds directly the angiotensin converting enzyme 2 (ACE2) cell receptors such as SARS-CoV, to infect humans. Also, ACE2 receptors are detected on glial cells and neurons in the brain [1]. According to current studies, alveolar epithelial cells, mucosa of oral cavity, intestine, kidney and heart express ACE2. ACE2 highly expresses in tongue than other oral cavity (buccal and gingival), and these studies show the mucosa of oral cavity is vulnerable to COVID-19 infection [7]. Entrance of SARSCoV-2 via the olfactory bulb is showed in mice model [9].

Many viruses such as rhinovirus, Para influenza, Epstein-Barr virus, and some coronavirus may lead to smell and taste disorders [9, 10]. Permanent smell disorders are induced by viral upper respiratory tract infections [11]. Current studies among patients show a relationship between COVID-19 infection and smell disorders (hyposmia, anosmia) and loss of taste (ageusia), however, olfactory disorder to be more prevalent than gustatory dysfunctions [2, 12]. According to some reports, patients with COVID-19 infection show an entire or little loss of taste and smell [13], without rhinorrhea or nasal obstruction [10].

The exact pathogenesis of SARS-CoV-2 that causes anosmia and ageusia remains unclear [14], but possible reasons about anosmia could be central nervous system (CNS) involvement and nasal epithelium damaged by the microorganisms [15]. These studies showed that coronavirus may infect the human CNS [13] through the nose near the olfactory epithelium [1] and may be neuroinvasive in humans [8]. The route of entrance of the coronaviruses is via olfactory nerves or peripheral trigeminal into the CNS, so COVID-19 can damage the trigeminal and olfactory nerve and cause dysosmia and dysgeusia [13], another probability of COVID-19 infection may cause to decrease the sensitivity of sensory neurons reflexes [8]. According to another theory, people popularly consume chemicals and disinfectants in the ongoing pandemic that may cause smell and taste disorders [13]. According to the clinical studies, post-viral anosmia is one of the reasons of smell disorders in adults and can be stable [15]. Recently, a research shows that SARS-CoV-2 RNA was isolated in the cerebrospinal fluid that suggests the neuroinvasiveness of SARS-CoV-2 [8]. However, there are some challenges about the smell and taste disorders in patients with COVID-19. The aim of the current review was to investigate the association of patients with COVID-19 with olfactory and gustatory dysfunctions in recent studies.

\section{Methods}

We conducted a narrative review to determine whether SARS$\mathrm{CoV}-2$ can affect the olfactory and gustatory system. Literature search was carried out in the databases of Scopus, PubMed, ScienceDirect, UpToDate, and Web of Science using the keywords in combination on the following search strategy:

A. [Coronavirus] OR [COVID-19] OR [SARS-CoV-2] OR [Novel Coronavirus] OR [2019-nCoV]

B. [Olfactory] OR [Gustatory] OR [Anosmia] OR [Parosmia] OR [Hyposmia] OR [Phantosmia] OR [Ageusia] OR [Microsmia] OR [Dysgeusia] OR [Parageusia]

C. $[\mathrm{A}]$ AND [B]

Inclusion criteria were as follows: language (Englishwritten studies), type of study (original papers, abstracts, reports, reviews, letters to the editor, and clinical trials), and publication date (from December 2019 to April 2020). We excluded documents with inappropriate topics including old data that were not relevant to the main objective of the study. Also, non-English articles, ongoing manuscripts and papers addressing non-human studies, or discussing COVID-19 symptoms in general, without reference to olfactory or gustatory dysfunctions were excluded.

Finally, we screened the titles and abstracts of retrieved documents to identify studies meeting the inclusion criteria. The appropriate full-text articles were included and their results were discussed to make the final selection. After reading the full text of all eligible papers, the researchers made the final decision for each study.

\section{Results}

In a recent review, we studied the current evidences on olfactory and gustatory dysfunctions of COVID-19. For this purpose, 336 documents were identified and after removing 
duplicate articles $(n=134), 370$ records were screened. By applying the inclusion and exclusion criteria, 346 articles were removed and finally 24 articles were reviewed in full text. Articles in the selection process are shown by the PRISMA diagram (Fig. 1).

In this study, we finally reviewed 24 documents including 21 articles (9 reports, 6 reviews, 5 letters to the editor, and 1 cross-sectional study) and three clinical trials. The reviewed studies were conducted in the USA $(n=4)$, UK $(n=4)$, Iran $(n=4)$, Spain $(n=2)$, Italy $(n=2)$, China $(n=2)$, France $(n=2)$, Norway $(n=1)$, Switzerland $(n=1)$, Cuba $(n=1)$ and Denmark $(n=1)$. Review of current studies has shown that anosmia, hyposmia (microsmia), ageusia and dysgeusia (parageusia) are symptoms of COVID-19 disease that occurs in some patients (Table 1). According to the findings, anosmia was the most common symptom $(n=23)$ among other olfactory and gustatory manifestations of COVID-19. The frequency of identified symptoms is shown in Fig. 2.

\section{Discussion}

COVID-19 infection with common symptoms such as fever and chills, cough and shortness of breath spread rapidly around the world [29, 30]. As the disease progressed and many people became infected with the virus, more symptoms such as gastrointestinal involvements, neurologic complications and neuropsychiatric symptoms were reported [17, 19, 31]. Evidences of anosmia and dysgeusia have also been published in recent days $[3,12,26]$. Therefore, in this study, we reviewed the olfactory and gustatory dysfunctions of COVID-19.
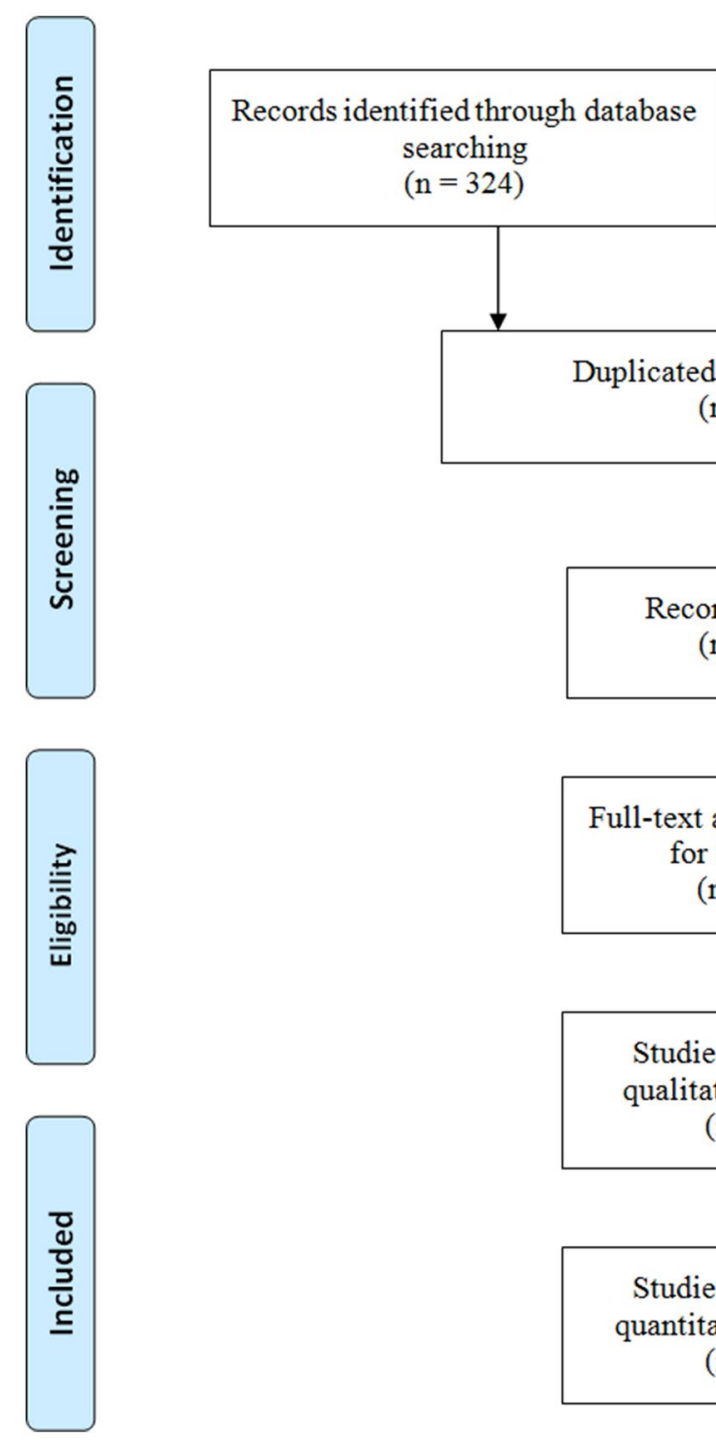

Duplicated articles removed

$(\mathrm{n}=125)$

Additional records identified through other sources $(\mathrm{n}=12)$

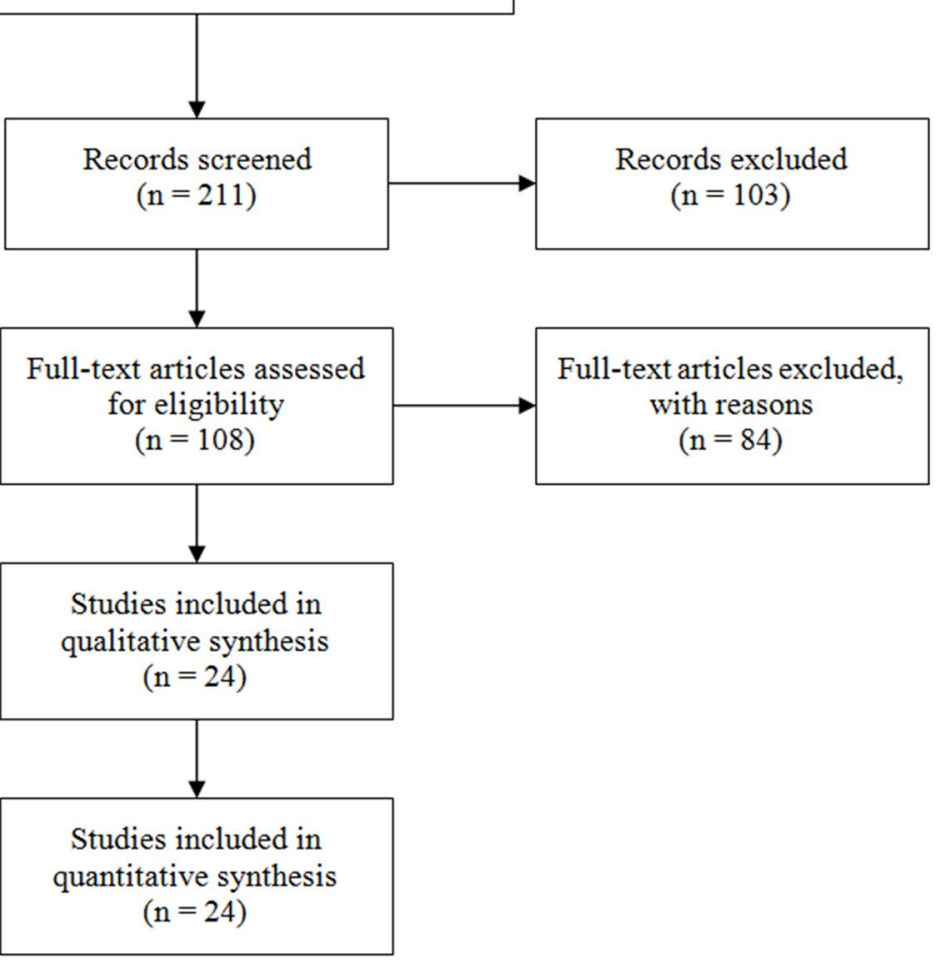

Fig. 1 PRISMA diagram of articles included 
Table 1 Identified olfactory/gustatory dysfunctions of COVID-19 based on the review of literature

\begin{tabular}{|c|c|c|c|c|c|c|c|c|}
\hline \multirow[t]{2}{*}{ ID } & \multirow[t]{2}{*}{ First author (reference) } & \multirow[t]{2}{*}{ Type of study } & \multirow[t]{2}{*}{ Country } & \multicolumn{5}{|c|}{ Olfactory/gustatory dysfunctions } \\
\hline & & & & Anosmia & $\begin{array}{l}\text { Hyposmia } \\
\text { (microsmia) }\end{array}$ & Ageusia & $\begin{array}{l}\text { Dysgeusia } \\
\text { (parageusia) }\end{array}$ & Other \\
\hline 1 & Russell B [12] & Report & UK & Yes & - & Yes & Yes & \\
\hline 2 & Machado C [2] & Review & Cuba & Yes & Yes & Yes & Yes & Dyssomnia-parosmia \\
\hline 3 & Villalba N [3] & Case report & Spain & Yes & Yes & - & Yes & - \\
\hline 4 & Ollarves-Carrero M [16] & Case report & Spain & Yes & Yes & - & Yes & Dysosmia-hypogeusia \\
\hline 5 & Troyer E [17] & Narrative review & USA & Yes & - & Yes & - & - \\
\hline 6 & Bagheri S [15] & Cross-sectional & Iran & Yes & Yes & Yes & - & Hypogeusia \\
\hline 7 & Ovesen T [11] & Case report & Denmark & Yes & Yes & Yes & - & - \\
\hline 8 & Gane S [18] & Case report & UK & Yes & - & Yes & - & - \\
\hline 9 & Pérez C [19] & Report & USA & Yes & Yes & Yes & Yes & - \\
\hline 10 & Hjelmesæth J [20] & Case report & Norway & Yes & Yes & Yes & Yes & - \\
\hline 11 & Gautier JF [21] & Letter to the editor & Switzerland & Yes & - & Yes & - & - \\
\hline 12 & Brann D [22] & Clinical trials & USA & Yes & Yes & - & - & - \\
\hline 13 & Lechien J [10] & Case Control & France & Yes & Yes & Yes & Yes & Phantosmia-parosmia \\
\hline 14 & Galougahi M [14] & Letter to the editor & Iran & Yes & Yes & - & - & Hypogeusia \\
\hline 15 & Hopkins C [23] & Clinical trials & UK & Yes & - & - & - & - \\
\hline 16 & Walker A [24] & Clinical trials & UK & Yes & Yes & - & Yes & - \\
\hline 17 & $\mathrm{Wu}$ Y [25] & Review & China & Yes & - & Yes & Yes & - \\
\hline 18 & Soler Z [26] & Review & USA & Yes & Yes & Yes & - & - \\
\hline 19 & Li Y [8] & Review & China & Yes & Yes & - & - & - \\
\hline 20 & Giacomelli A [9] & Letter to the editor & Italy & Yes & - & - & Yes & Dysosmia \\
\hline 21 & Eliezer M [27] & Case report & France & Yes & - & - & - & - \\
\hline 22 & Lovato A [1] & Review & Italy & Yes & Yes & - & - & $\begin{array}{l}\text { At least one taste or } \\
\text { olfactory disorder }\end{array}$ \\
\hline 23 & Keyhan SO [13] & Letter to the editor & Iran & - & - & - & Yes & Dysosmia \\
\hline 24 & Ghiasvand F (28) & Letter to the editor & Iran & Yes & - & - & - & - \\
\hline
\end{tabular}

Fig. 2 Frequencies of COVID19 olfactory and gustatory dysfunctions
Olfactory/Gustatory Dysfunctions

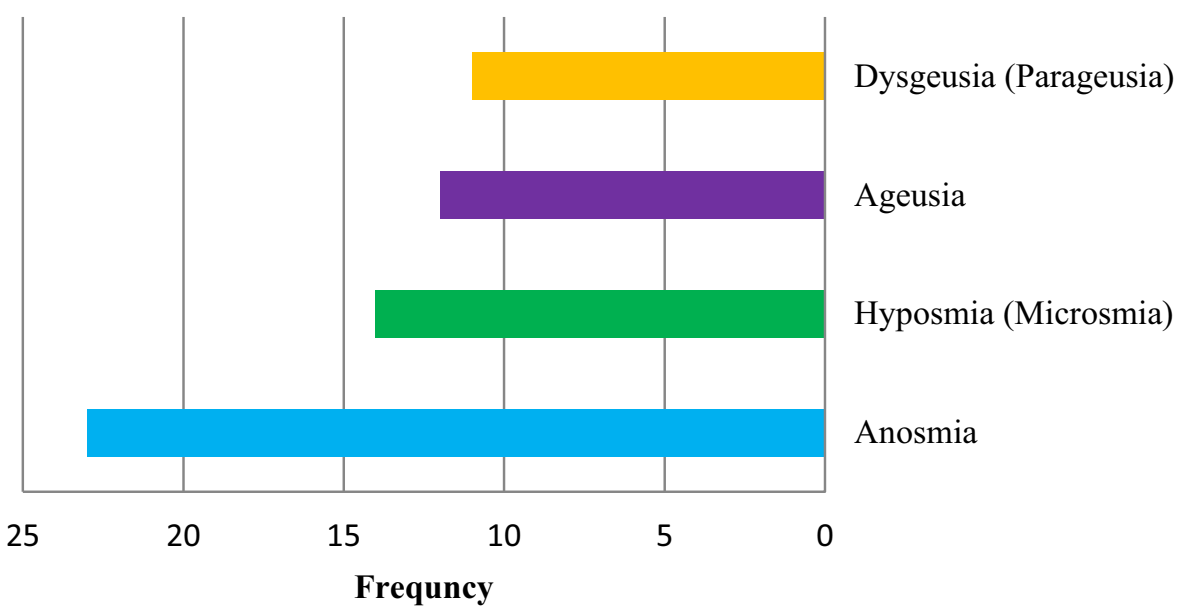

Our review study showed that patients with COVID19 infection may have loss of taste or smell as the symptom. Most studies (95.8\%) have confirmed the symptoms of anosmia in patients with SARS-CoV-2 infection [1-3,
8-12, 14-28]. It is therefore likely that a surge in the spread of olfactory abnormalities happened during the epidemic of COVID-19 infection [1, 22]. Rather than injury to the structure of the receptors, the virus has been suggested to 
cause some kind of inflammation in the olfactory nerves [3]. However, researchers' findings suggest that the exact mechanism of olfactory and gustatory dysfunctions requires further investigation $[11,15]$.

Anosmia has been anecdotally reported as a distinct symptom in patients who have been diagnosed with COVID19 in other studies [2, 3, 12, 16, 17]. However, existing cohort studies have not highlighted these symptoms, and the frequency and effectiveness of COVID-19 for these symptoms is not yet conclusive [3, 9]. The findings of Ghiasvand et al.'s study have implied that anosmia is a new symptom of COVID-19 infection and more research is needed to find how the virus affects patients' olfactory system [28].

Anosmia is particularly seen in patients positive for the coronavirus who do not have any other clinical symptoms [3]. Gane et al., in a case report study, have reported a patient presenting with isolated sudden onset anosmia (ISOA) who went on to test positive for COVID-19 infection and did not develop any further symptoms such as respiratory or gastrointestinal symptoms that other patients may have [18]. Similarly, Eliezer et al. showed that the association of a sudden and complete olfactory function loss, without nasal obstruction in a patient with other symptoms, such as cough or fever, should alert the clinician to suspect SARS-CoV-2 infection [27]

Review of current studies showed that, in addition of anosmia, evidences of ageusia and dysgeusia (parageusia) were also seen in patients with COVID-19 [2, 10, 19, 20, 25]. The possibility that SARS-CoV-2 might cause olfactory and gustatory dysfunctions is certainly acceptable [26]. Current studies indicated that hyposmia or anosmia and dysgeusia may be an early symptom associated with the COVID-19 infection [12, 19, 25].

A growing number of patients with SARS-CoV-2 infection report a sudden loss of smell or taste functions. It seems that anosmia and dysgeusia might be observed in COVID19 patients [25]. Based on a case control study results, the COVID-19-infected patients may just present olfactory and gustatory dysfunctions without other significant symptoms. The only anosmia or ageusia symptom needs to be recognized by the infectious diseases specialists as an important symptom of the SARS-CoV-2 infection [10].

Other similar studies have confirmed the above-mentioned clinical manifestations [1, 2, 20]; for example, Machado in a review study concluded that because the existence of a relationship between post-infectious manifestations and COVID-19 is likely, it is highly recommended that those patients who experience complications such as smell and/ or taste loss, even as only symptoms, should be considered as potential SARS-CoV-2 infection carriers [2]. Moreover, Hjelmesæth et al., in a case report study have concluded that patients with SARS-CoV-2 infection may have loss of taste or smell as the only symptom [20].

\section{Conclusion}

Although there have been few reports of definite change in smell and taste perception in patients with COVID-19, the findings of these studies raise the question whether SARSCoV-2 may cause olfactory and gustatory dysfunctions [2, 13, 21, 22]. The results of our study support recent reports that SARS-CoV-2 may infect oral and nasal tissues and cause olfactory and gustatory dysfunctions. These findings may aid future research on the diagnosis, prevention and treatment of COVID-19 consequences.

\section{Compliance with ethical standards}

Conflict of interests There is no conflict of interest.

\section{Reference}

1. Lovato A, de Filippis C, Marioni G (2020) Upper airway symptoms in coronavirus disease 2019 (COVID-19). Am J Otolaryngol 41(3): 102474

2. Machado C, Gutierrez J (2020) Anosmia and ageusia as initial or unique symptoms after SARS-CoV-2 virus infection. Preprints 2020040272:1020944

3. Villalba NL, Maouche Y, Ortiz MB, Sosa ZC, Chahbazian JB, Syrovatkova A, Pertoldi P, Andres E, Zulfiqar AA (2020) Anosmia and dysgeusia in the absence of other respiratory diseases: should COVID-19 infection be considered? Eur J Case Rep Internal Med 7(4):001641

4. Asadollahi-Amin A, Hasibi M, Ghadimi F, Rezaei H, SeyedAlinaghi S (2020) Lung involvement found on chest ct scan in a presymptomatic person with SARS-CoV-2 infection: a case report. Trop Med Infect Dis 5(2):56

5. Salehi S, Abedi A, Balakrishnan S, Gholamrezanezhad A (2020) Coronavirus disease 2019 (COVID-19): a systematic review of imaging findings in 919 patients. Am J Roentgenol 1-7

6. Ghiasvand F, Miandoab SZ, Harandi H, Golestan FS, Alinaghi SA (2020) A patient with COVID-19 disease in a Referral Hospital in Iran: a typical case. Infect Disord Drug Targets. https://doi. org/10.2174/1871526520666200429115535

7. Xu H, Zhong L, Deng J, Peng J, Dan H, Zeng X, Li T, Chen Q (2020) High expression of ACE2 receptor of 2019-nCoV on the epithelial cells of oral mucosa. Int J Oral Sci 12(1):1-5

8. Holshue ML, DeBolt C, Lindquist S, Lofy KH, Wiesman J, Bruce H, Spitters C, Ericson K, Wilkerson S, Tural A, Diaz G (2020) First case of 2019 novel coronavirus in the United States. N Engl J Med. https://doi.org/10.1056/NEJMoa2001191

9. Giacomelli A, Pezzati L, Conti F, Bernacchia D, Siano M, Oreni L, Rusconi S, Gervasoni C, Ridolfo AL, Rizzardini G, Antinori S, Galli M (2020) Self-reported olfactory and taste disorders in patients with severe acute respiratory coronavirus 2 infection: a cross-sectional study. Clin Infect Dis. https://doi.org/10.1093/cid/ ciaa330

10. Lechien JR, Chiesa-Estomba CM, De Siati DR, Horoi M, Le Bon SD, Rodriguez A et al (2020) Olfactory and gustatory dysfunctions as a clinical presentation of mild-to-moderate forms of the coronavirus disease (COVID-19): a multicenter European study. Eur Arch Otorhinolaryngol 6:1-1 
11. Ovesen T (2020) COVID-19 anosmia. Tidsskrift for Den norske legeforening 104045

12. Russell B, Moss C, Rigg A, Hopkins C, Papa S, Van Hemelrijck M (2020) Anosmia and ageusia are emerging as symptoms in patients with COVID-19: what does the current evidence say? Ecancermedicalscience 14:103332

13. Keyhan SO, Fallahi HR, Cheshmi B (2020) Dysosmia and dysgeusia due to the 2019 Novel Coronavirus; a hypothesis that needs further investigation. SpringerOpen 101186

14. Galougahi MK, Ghorbani J, Bakhshayeshkaram M, Naeini AS, Haseli S (2020) Olfactory bulb magnetic resonance imaging in SARS-CoV-2-induced anosmia: the first report. Acad Radiol 101016

15. Bagheri SHR, Asghari AM, Farhadi M, Shamshiri AR, Kabir A, Kamrava SK et al (2020) Coincidence of COVID-19 epidemic and olfactory dysfunction outbreak. medRxiv. https://doi.org/10.34171 /mjiri.34.62

16. Ollarves-Carrero MF, Rodriguez-Morales AG, Bonilla-Aldana DK, Rodriguez-Morales AJ (2020) Anosmia in a healthcare worker with COVID-19 in Madrid, Spain. Travel Med Infect Dis. https://doi.org/10.1016/j.tmaid.2020.101666

17. Troyer EA, Kohn JN, Hong S (2020) Are we facing a crashing wave of neuropsychiatric sequelae of COVID-19? Neuropsychiatric symptoms and potential immunologic mechanisms. Brain Behav Immun. https://doi.org/10.1016/j.bbi.2020.04.027

18. Gane S, Kelly C, Hopkins C (2020) Isolated sudden onset anosmia in COVID-19 infection. A novel syndrome? Rhinology 104193

19. Pérez CA (2020) Looking ahead: the risk of neurologic complications due to COVID-19. Neurol Clin Pract. https://doi. org/10.1212/CPJ.0000000000000836

20. Hjelmesæth J, Skaare D (2020) Loss of smell or taste as the only symptom of COVID-19. Tidsskrift for Den norske legeforening. https://doi.org/10.4045/tidsskr.20.0287

21. Gautier JF, Ravussin Y (2020) A new symptom of COVID-19: loss of taste and smell. Obesity. https://doi.org/10.1002/oby.22809

22. Brann D, Tsukahara T, Weinreb C, Logan DW, Datta SR (2020) Non-neural expression of SARS-CoV-2 entry genes in the olfactory epithelium suggests mechanisms underlying anosmia in COVID-19 patients. bioRxiv. https://doi. org/10.1101/2020.03.25.009084
23. Hopkins C, Surda P, Kumar N (2020) Presentation of new onset anosmia during the COVID-19 pandemic. Rhinology. https://doi. org/10.4193/Rhin20.116.

24. Walker A, Hopkins C, Surda P (ed) (2020) The use of google trends to investigate the loss of smell related searches during COVID-19 outbreak. Int Forum Allergy Rhinol. Wiley Online Library. https://doi.org/10.1002/alr.22580

25. Wu Y, Xu X, Chen Z, Duan J, Hashimoto K, Yang L, et al (2020) Nervous system involvement after infection with COVID19 and other coronaviruses. Brain Behav Immun. https://doi. org/10.1016/j.bbi.2020.03.031

26. Soler ZM, Patel ZM, Turner JH, Holbrook EH (eds) (2020) A primer on viral-associated olfactory loss in the era of COVID-19. Int Forum Allergy Rhinol. Wiley Online Library. https://doi. org/10.1002/alr.22578

27. Eliezer M, Hautefort C, Hamel A-L, Verillaud B, Herman P, Houdart E et al (2020) Sudden and complete olfactory loss function as a possible symptom of COVID-19. JAMA Otolaryngol Head Neck Surg. https://doi.org/10.1001/jamaoto.2020.0832

28. Ghiasvand F, SeyedAlinaghi S (2020) Isolated anosmia as a presentation of COVID-19: an experience in a referral hospital. Infect Disord Drug Targets. https://doi.org/10.2174/187152652099920 0520173216

29. Mehraeen E, Hayati B, Saeidi S, Heydari M, Seyedalinaghi S (2020) Self-care instructions for people not requiring hospitalization for coronavirus disease 2019 (COVID-19). Arch Clin Infect Dis.15(COVID-19). https://doi.org/10.5812/archcid.102978

30. Ahmadinejad ZDO, SeyedAlinaghi S (2020) Pleural effusion as an initial sign of coronavirus disease 2019 (COVID 19) pneumonia: a case report. Infect Dis Drug Targets. https://doi. org/10.2174/1871526520666200609125045

31. Gu J, Han B, Wang J (2020) COVID-19: gastrointestinal manifestations and potential fecal-oral transmission. Gastroenterology 158(6):1518-1519

Publisher's Note Springer Nature remains neutral with regard to jurisdictional claims in published maps and institutional affiliations. 